\title{
Typical changes of ethmocephaly and holoprosencephaly in a fetus at 14 weeks of gestation
}

\author{
${ }^{1}$ Department of Gynecology, Obstetrics and Gynecological Endocrinology, Kepler University Hospital, Johannes Kepler Univer- \\ sity Linz, Linz, Austria, E-mail: reinhard.altmann@me.com. https://orcid.org/0000-0001-9227-724X. \\ 2 Department of Prenatal Medicine, Kepler University Hospital, Linz, Austria, E-mail: reinhard.altmann@me.com. \\ https://orcid.org/0000-0001-9227-724X.
}

\begin{abstract}
:
Background: This case report is to show the details of the face of a very rare ethmocephaly at 14 weeks of gestation.

Case presentation: After the regular transabdominal two-dimensional (2D) scan for nuchal translucency we could describe the following malformations: holoprosencephaly, proboscis and an abnormal face, omphalocele containing bowel, hyperechoic kidneys and megacystis. In addition, we acquired transvaginal threedimensional (3D) ultrasound volume blocks of the fetal head, scanned with different insonation angles and stored them for later analysis. Using the multiplanar mode the volume blocks taken from the front show all details of the face: proboscis, hypotelorism, microphthalmia, cleft palate, accelerated development of the frontal bones and premature closure of the metopic suture. The volume blocks taken through the squamosal suture show all details of the fossa posterior and brain: fused thalami surrounded by the typical monoventricle, normal brain stem, elongation of anterior membranous area. Render mode shows a precise 3D image of the face. To better demonstrate the changes of the fetal face a post-mortem photo of the fetal face is included.

Conclusion: This case report can demonstarte the typical changes of ethmocephaly in the first trimester using transvaginal 3D scan.
\end{abstract}

Keywords: Ethmocephaly, fetal brain, fetal face, fossa posterior, holoprosencephaly, proboscis, transvaginal 3D sonography

DOI: $10.1515 / \mathrm{crpm}-2018-0042$

Received: August 7, 2018; Accepted: April 30, 2019

\section{Introduction}

Holoprosencephaly is a severe cerebral malformation showing disturbance of the sagittal cleavage of the embryonic prosencephalon into hemispheres, the transversal cleavage into telencephalon and diencephalon and the horizontal cleavage into olfactory and optic bulbs [1], [2]. The malformation typically occurs in the $5^{\text {th }}$ and $6^{\text {th }}$ gestational week. Ethmocephaly lies in the midst of the holoprosencephalic spectrum, classically manifesting with hypoteloric eyes, separate orbits and interorbital proboscis [3], [4]. The spectrum encompasses normocephaly, mild facial dysmorphism, median cleft lip, cebocephaly, ethmocephaly and cyclopia [5], [6]. The holoprosencephalic spectrum shows the correlation between the extent of brain changes and the extent of facial dysmorphism. Pronounced forms of holoprosencephaly are associated with characteristic mid-face anomalies in $70-80 \%$ of cases, in contrast to mild forms where the deviation from the normal anatomy of the face is marginally.

\section{Case presentation}

A 22-year-old gravida 2, para 1 was referred to our unit for a detailed $1^{\text {st }}$ trimester scan at crown-rump-length of $84 \mathrm{~mm}$ presenting with adverse ultrasound findings. Using the two-dimensional (2D) scan, we found a typical 
alobar holoprosencephaly, exomphalos containing bowel $(10.5 \times 10.6 \mathrm{~mm})$, megacystis [2], [7] (bladder length $15.7 \mathrm{~mm}$ ) and a nuchal translucency of $4.8 \mathrm{~mm}$. The fetal heart rate was $153 \mathrm{bpm}$. The face transabdominally showed a strange appearance with a protruding mouth and a flat nose and forehead [8]. For a better sight we changed to transvaginal ultrasound including three-dimensional (3D) samples in addition. Transvaginal 3D ultrasound showed the following additional findings: large hyperechoic kidneys (right: $8.78 \times 7.97 \times 14.8 \mathrm{~mm}$, left: $7.48 \times 6.43 \times 14.0$ ), ethmocephaly including proboscis, hypotelorism, microphthalmia, cleft palate and hypoplasia of the vermis. After informing the parents about the fetal malformations, the woman asked for the termination of the pregnancy, refusing the search for a genetic syndrome and refusing the autopsy. Described in the following are the details of the 3D scan of the fetal face and brain we found.

\section{Face sagittal (Figure 1-Figure 3)}

In the mid sagittal plane, the proboscis is the most notable structure, appearing as a nasal appendage, typically arising from the ethmoid bone, turning upward and opening with a single nostril [1], [9] (Figure 1). Directly under the ethmoid bone, the aperture of the eyelid is situated in the midline, caudally the face is flat, the nose is absent. Using a different insonation angel maxillary gap measuring $2.7 \mathrm{~mm}$ (normal $<1.5 \mathrm{~mm}$ ) and palatinomaxillary diameter (Figure 3$)$ measuring $1.2 \mathrm{~mm}\left(<5^{\text {th }}\right.$ centile) as a marker of cleft palate are displayed [10], [11].

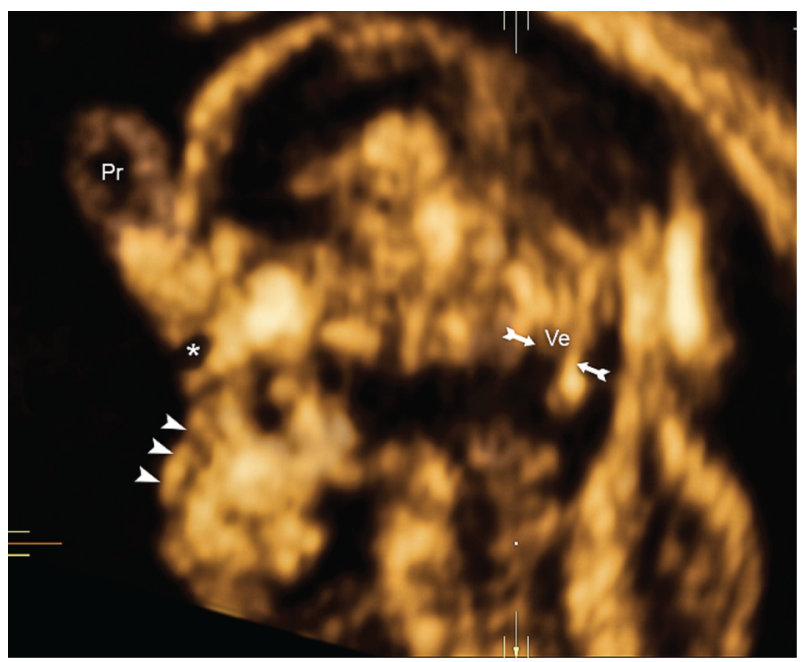

Figure 1: Median sagittal: arrowhead, absent nose; asterisk, lid opening; arrow, Ve, vermis; Pr, proboscis.

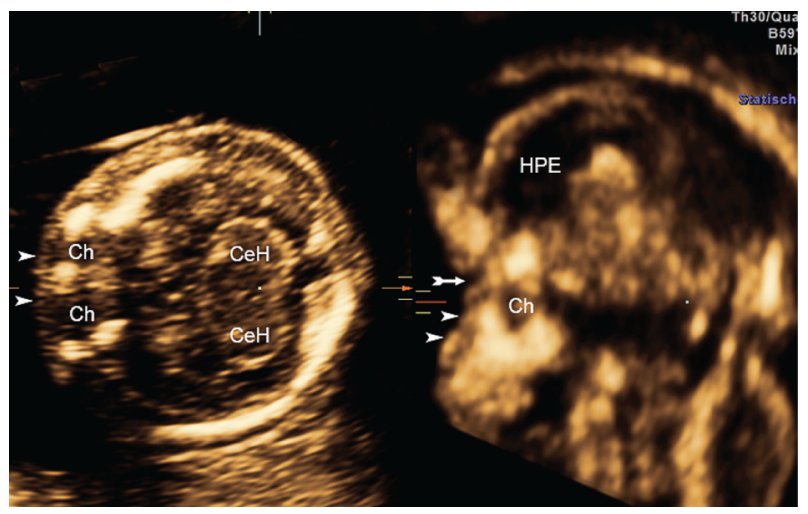

Figure 2: Axial, paramedian sagittal: Ch, choanal atresia; arrow, lid opening; arrowhead, absent nose; HPE, holoprosencephaly; $\mathrm{CeH}$, hemisphere of the cerebellum. 


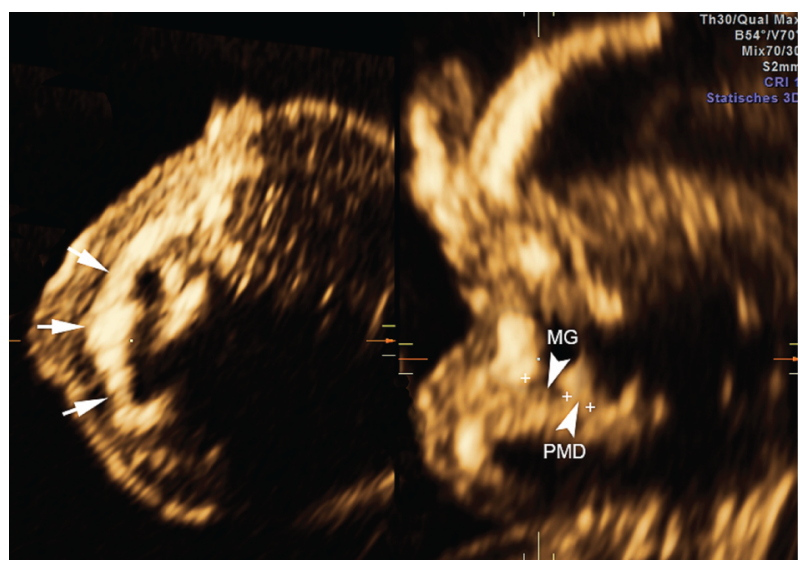

Figure 3: Axial, median sagittal: arrow, maxillary bone without suture; arrowhead, MG maxillary gap, PMD, palatinomaxillary diameter.

\section{Face axial (Figure 2-Figure 5)}

The axial plane with the ethmoid bone in the middle shows microphthalmia [ocular diameter (OD 2.8/3.0 $\mathrm{mm}$ ) on both sides of the ethmoid bone, close to the ethmoid bone and close to each other [interocular distance (IOD) 5,8 mm] (hypotelorism) [12], [13], [14], [15], [16], [17] (Figure 4). The plane underneath the eyes and the proboscis presents with the aperture of the eyelid in the middle. Caudally to this plane the facial skeleton presents with two approximately round structures close to the midline, representing choanal atresia (Figure 2 ), resulting from the coalescence of the pterygoid plate and palatine bones. The processus alveolares maxillae form a thickened plate as a result of disturbed development of the maxillary suture [18].

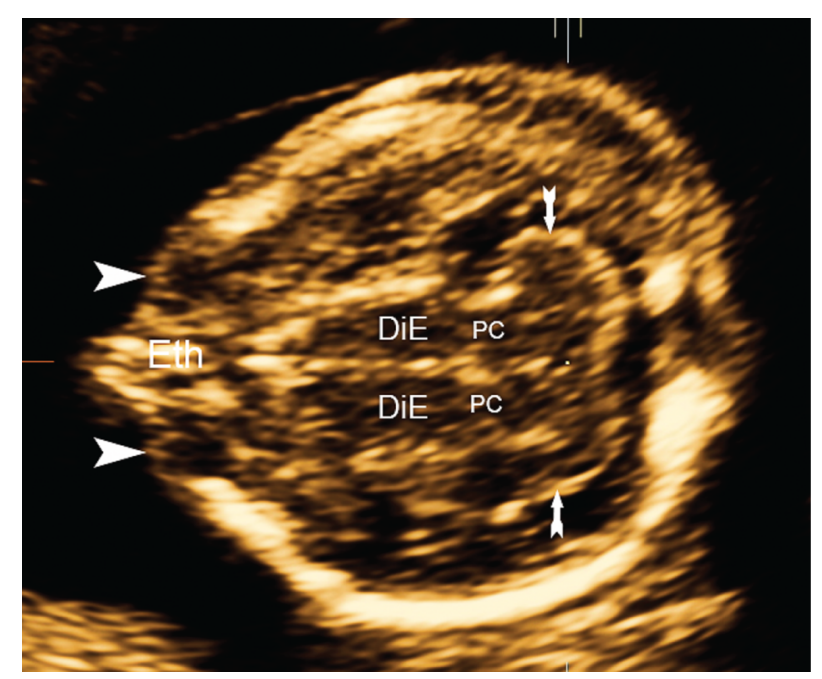

Figure 4: Axial: arrowhead, eyes (microphthalmia, hypotelorism); Eth, ethmoid bone; DiE, diencephalon; PC, pedunculi cerebri; arrow, transcerebellar diameter. 


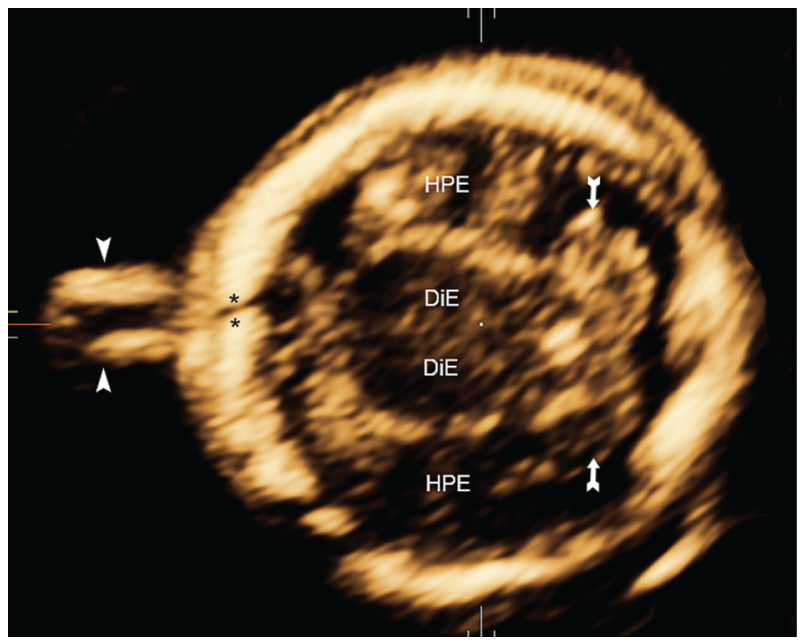

Figure 5: Axial: arrowhead, proboscis; DiE, diencephalon; HPE, holoprosencephaly; arrow, cerebellum; asterisk, metopic suture.

\section{Face coronal (Figure 6)}

Selecting a coronal section of the fetal head the height of the frontal bone [11 $\mathrm{mm}(4.5-8 \mathrm{~mm})]$ and the transvers gap of the metopic suture [0.6 mm (1-2 mm)] are visible [19] (Figure 6). Accelerated development of the frontal bones and premature closure of the metopic suture are typical changes associated with alobar holoprosencephaly.

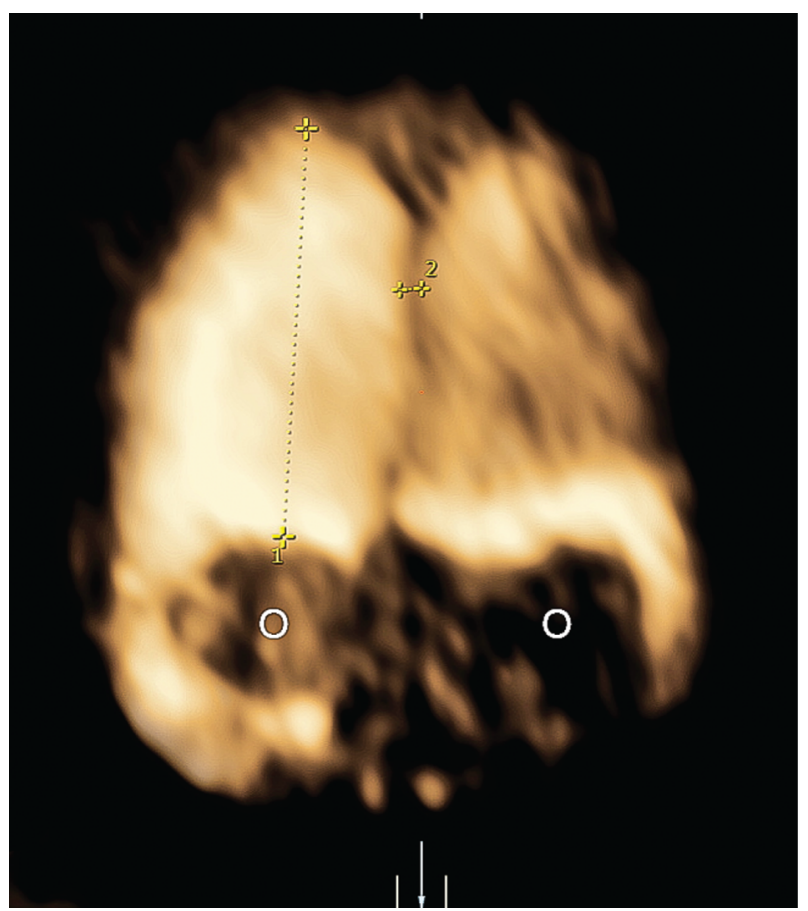

Figure 6: Coronal: $\mathrm{O}$, orbita; 1, height of the frontal bone; 2, distance of the metopic suture.

\section{CNS axial (Figure 4 and Figure 5)}

Using axial planes the alobar holoprosencephaly can be seen showing the fused thalami surrounded by the typical monoventricle. The absence of the falx cerebri can be displayed as well as a typical sign of holoprosencephaly. Transverse cerebellar diameter (TCD) of the cerebellum $(13 \mathrm{~mm}$ ) is within the normal range (Figure $4)$. 


\section{CNS sagittal (Figure 1)}

The median sagittal plane shows the monoventricle cranially to the thalami. The structures of the fossa posterior show a small vermis $\left(3.2 \mathrm{~mm}\right.$ - at the $5^{\text {th }}$ percentile), whenever the brain stem shows a normal appearance: pons diameter $2.7 \mathrm{~mm}$, diameter of medulla oblongata $2.6 \mathrm{~mm}$, medulla oblongata angle $139^{\circ}$. The anterior membranous area was $0 \mathrm{~mm}$, posterior membranous area showed $5 \mathrm{~mm}>95^{\text {th }}$ percentile [20].

\section{Discussion}

This case report presents the typical details of a very rare case of ethmocephaly $(0.06 \%)$ as part of the holoprosencephalic spectrum. Ethmocephaly is a well-defined malformation of the face including hypoteloric eyes, separate orbits and interorbital proboscis. It is typically associated with alobar holoprosencephaly.

This case report can demonstrate, that it is possible to display all details of the fetal face and brain very early in pregnancy, when doing $1^{\text {st }}$ trimester screening. Therefore, it is useful to add a transvaginal 3D volume scan to the transabdominal 2D scan, usually done in this week for nuchal translucency and $1^{\text {st }}$ trimester screening. As we already could demonstrate in our publication about the sonoembryology of the fossa posterior [20], [21], it is useful to do the 3D scan for details of the fossa posterior. In this case report we additionally show that the face can also be displayed in great detail, when using transvaginal 3D scan from a frontal insonation angle.

The mid sagittal view of the face shows the typical reduced ossified area of cleft palate [22], presenting with both recently published signs: the enlargement of maxillary gap and the shortening of palatino-maxillary diameter [10], [11]. Anterior to the cleft palate the processus alveolares maxillae present thickened and buckled [18].

In addition, accelerated development of the frontal bones and premature closure of the metopic suture as a typical sign of holoprosencephaly can be demonstrated [19]. Measurement of interlens and interorbital/biorbital distance can demonstrate hypotelorism, measurement of the orbit (distance) and lens (diameter, circumference, area) demonstrate microphthalmia.

Holoprosencephaly has been an easily displayable detail of the fetal brain scanned transabdominally with 2D technique, even in earlier weeks of gestation, it is now possible to scan more details of the fetal brain using transvaginal 3D volume blocks. Especially as demonstrated in earlier publications details of the fossa posterior can be shown. In this case the vermis is at the $5^{\text {th }}$ percentile, the brainstem (diameter of medulla oblongata / pons and medulla oblongata pons angle) shows normal values, the anterior membranous area is $0 \mathrm{~mm}$, as part of the normal development. In contrast the posterior membranous area shows abnormal elongation $\left(>95^{\text {th }}\right.$ percentile) [20], [21].

In order to visualize the fetal face, it is possible to use the stored 3D blocks to create a three-dimensional picture (Figure 7) by using render mode showing the same changes as the post-mortem photo (Figure 8).

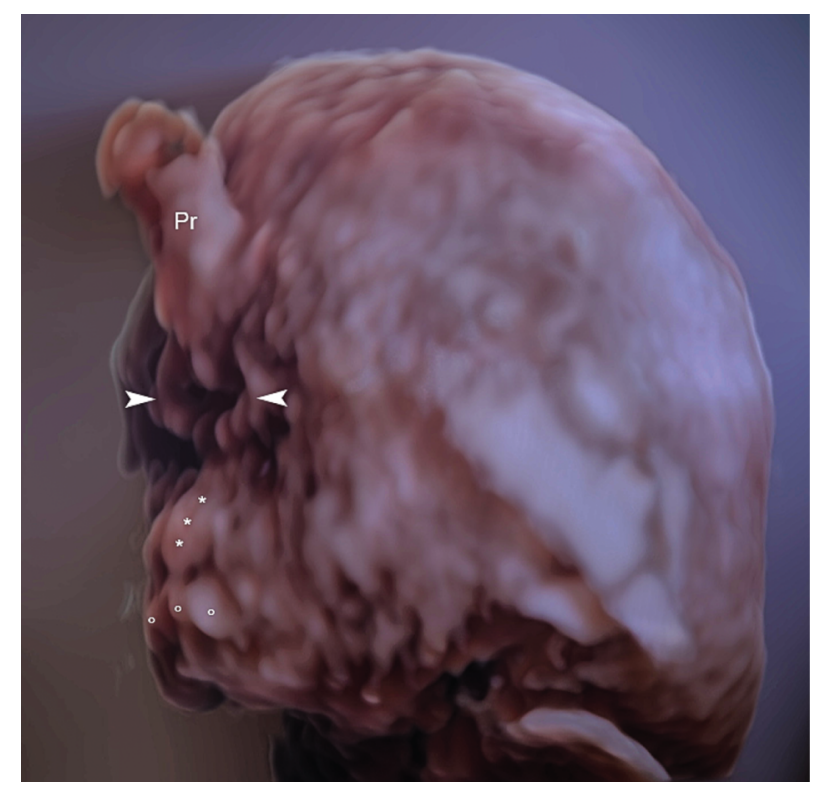

Figure 7: Render: Pr, proboscis; arrowhead, lid opening; asterisk, absent nose; ring, upper lip. 


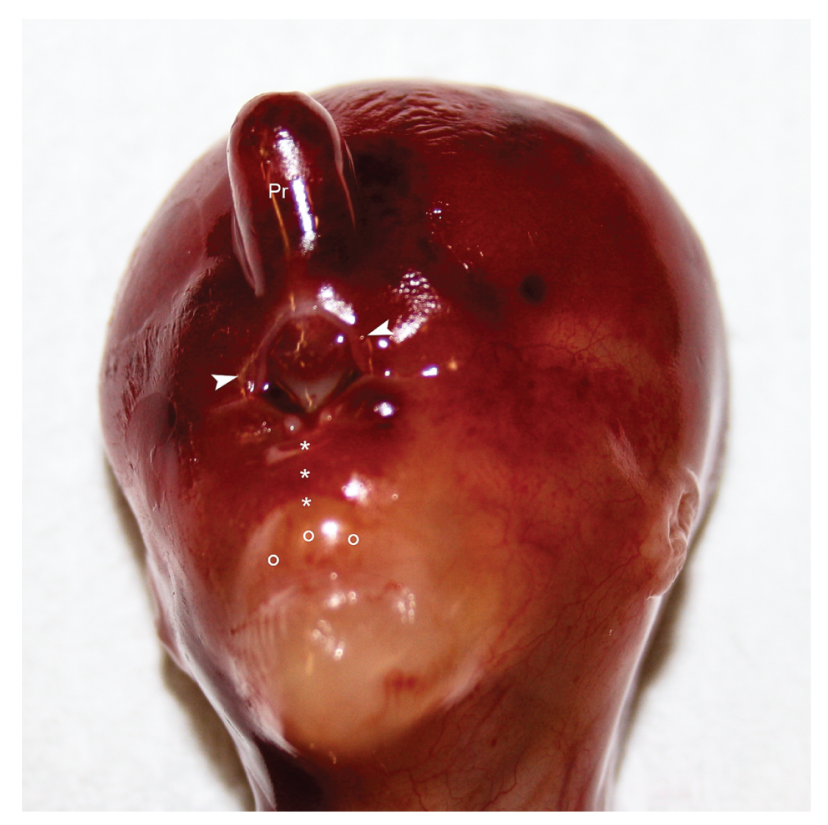

Figure 8: Photo: Pr, proboscis; arrowhead, lid opening; asterisk, absent nose; ring, upper lip.

Ethical approval: The research related to human use has complied with all the relevant national regulations, institutional policies and has been conducted in accordance with the tenets of the Helsinki Declaration, and it has been approved by the authors' Institutional Review Board or equivalent committee.

Author contributions: All the authors have accepted responsibility for the entire content of this submitted manuscript and approved submission.

Research funding: None declared.

Employment or leadership: None declared.

Honorarium: None declared.

Competing interests: The funding organization(s) played no role in the study design; in the collection, analysis, and interpretation of data; in the writing of the report; or in the decision to submit the report for publication.

\section{References}

[1] Tonni G, Ventura A, Centini G, De Felice C. First trimester three-dimensional transvaginal imaging of alobar holoprosencephaly associated with proboscis and hypotelorism (ethmocephaly) in a 46,XX fetus. Congenit Anom (Kyoto). 2008;48:51-5.

[2] Kagan KO, Staboulidou I, Syngelaki A, Cruz ], Nicolaides KH. The 11-13-week scan: diagnosis and outcome of holoprosencephaly, exomphalos and megacystis. Ultrasound Obstet Gynecol. 2010;36:10-4.

[3] DeMyer W. The median cleft face syndrome. Differential diagnosis of cranium bifidum occultum, hypertelorism, and median cleft nose, lip, and palate. Neurology. 1967;17:961-71.

[4] DeMyer W, Zeman W, Gardella Palmer C. The face predicts the brain: diagnostic significance of median facial anomalies for holoprosencephaly (arhinencephaly). Pediatrics. 1964;34:256-63.

[5] Souza ], Siebert ], Beckwith ]. An anatomic comparison of cebocephaly and ethmocephaly. Teratology. 1990;42:347-58.

[6] Yoshinaga K, Miyayama Y, Fujimoto T. An autopsy case of ethmocephaly. Okajimas Folia Anat ]pn. 1982;58:883-90.

[7] Taghavi K, Sharpe C, Stringer MD, Zuccollo ], Marlow ]. Fetal megacystis: institutional experience and outcomes. Aust N Z ] Obstet Cynaecol. 2017;57:636-42.

[8] Hoopmann M, Kagan KO. The fetal profile - more than just NT. Ultraschall Med. 2017;38:611-8.

[9] Socolov D, Iliev G, Scripcaru D, Gorduza V, Socolov RV, Puiu M. Trisomy 13 with cyclopia and proboscis a case presentation. Jurnalul Pediatrulu. 2009;12:16-8.

[10] Chaoui R, Orosz G, Heling KS, Sarut-Lopez A, Nicolaides KH. Maxillary gap at 11-13 weeks' gestation: marker of cleft lip and palate. Ultrasound Obstet Gynecol. 2015;46:665-9.

[11] Lachmann R, Schilling U, Bruckmann D, Weichert A, Bruckmann A. Isolated cleft lip and palate: maxillary gap sign and palatinomaxillary diameter at 11-13 weeks. Fetal Diagn Ther. 2018;44:241-6.

[12] Mayden KL, Tortora M, Berkowitz RL, Bracken M, Hobbina JC. Orbital diameters: a new parameter for prenatal diagnosis and dating. Am J Obstet Gynecol. 1982;144:289-97. 
[13] RosatiP BF, Guariglia L. Reference values of fetal orbital measurements by transvaginal scan in early pregnancy. Prenat Diagn. 2002;22:851-5.

[14] Paolo Rosati M, Guariglia L. Early transvaginal fetal orbital measurements. ] Ultrasound in Medicine. 2003;22:1201-5

[15] Coldstein I, Tamir A, Zimmer EZ, Itskovitz-Eldor ]. Growth of the fetal orbit and lens in normal pregnancies. Ultrasound Obstet Cynecol. 1998;12:175-9.

[16] Kivilevitch Z, Salomon L], Benoit B, Achiron R. Fetal interlens distance: normal values during pregnancy. Ultrasound Obstet Gynecol. 2010;36:186-90.

[17] Rosati P, Guariglia L. Transvaginal fetal biometry in early pregnancy. Early Hum Dev. 1997;49:91-6.

[18] Souza JP, Siebert ]R, Beckwith JB. An anatomic comparison of cebocephaly and ethmocephaly. Teratology. 1990;42:347-57.

[19] Faro C, Wegrzyn P, Benoit B, Chaoui R, Nicolaides KH. Metopic suture in fetuses with holoprosencephaly at $11+0$ to $13+6$ weeks of gestation. Ultrasound Obstet Cynecol. 2006;27:162-6.

[20] Altmann R, Scharnreitner I, Scheier T, Mayer R, Arzt W, Scheier M. Sonoembryology of the fetal posterior fossa at 11+3 to 13+6 gestational weeks on three-dimensional transvaginal ultrasound. Prenat Diagn. 2016;36:731-7.

[21] Altmann R, Specht C, Scharnreitner I, Schertler C, Mayer R, Arzt W, et al. Reference ranges for transvaginal examined fossa posterior structures in fetuses from 45 to $84 \mathrm{~mm}$ crown-rump length. Cynecol Obstet Invest. 2018;83:375-80.

[22] Chi T, Perolo A, Banzi C, Contratti G, Valeri B, Savelli L, et al. Two-dimensional ultrasound is accurate in the diagnosis of fetal craniofacial malformation. Ultrasound Obstet Gynecol. 2002;19:543-51. 